\section{Andamios Revista de Investigación Social}

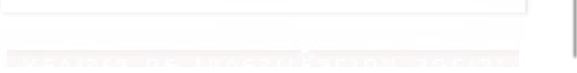

\author{
Andamios. Revista de Investigación \\ Social \\ ISSN: 1870-0063 \\ revistaandamios@uacm.edu.mx \\ Universidad Autónoma de la Ciudad de \\ México \\ México
}

Serrano Gómez, Enrique

Derechos fundamentales y justicia distributiva

Andamios. Revista de Investigación Social, vol. 8, núm. 15, enero-abril, 2011, pp. 189-214

Universidad Autónoma de la Ciudad de México

Distrito Federal, México

Disponible en: http://www.redalyc.org/articulo.oa?id=62819892009

- Cómo citar el artículo

- Número completo

- Más información del artículo

- Página de la revista en redalyc.org

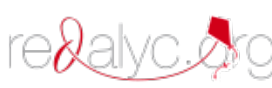

Sistema de Información Científica

Red de Revistas Científicas de América Latina, el Caribe, España y Portugal

Proyecto académico sin fines de lucro, desarrollado bajo la iniciativa de acceso abierto 


\section{Artículos}

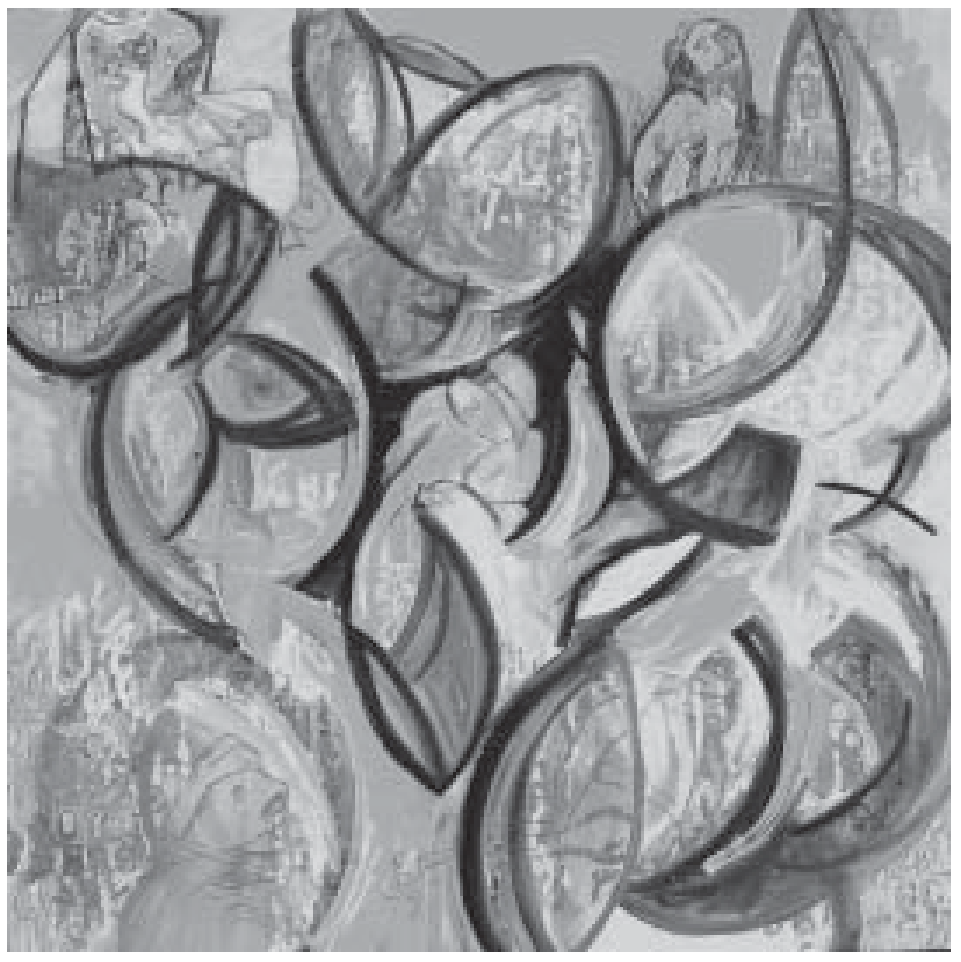

Sin título, Luis Ramos 


\title{
DERECHOS FUNDAMENTALES Y JUSTICIA DISTRIBUTIVA
}

\author{
Enrique Serrano Gómez*
}

\begin{abstract}
Resumen: El objetivo de este trabajo es desarrollar una defensa interna de la inclusión de los derechos sociales en el catálogo de los derechos fundamentales. Se califica de interna esta defensa porque se trata de fundamentar la tesis de que dicha inclusión representa un elemento necesario para la realización del sentido del derecho. A diferencia de la tradición positivista, la cual consideraba que era posible realizar una descripción del ordenamiento jurídico valorativamente neutra, lo que se plantea es que el derecho, en tanto artificio social, responde a un sentido, el cual debe ser comprendido para realizar una labor descriptiva adecuada. En la medida en que la dinámica del derecho presuponela libertad de todos los participantes (las acciones les pueden ser imputadas), su sentido está constituido por las condiciones que permiten el ejercicio de esa libertad. Esta estrategia de defensa de los derechos sociales fue la aportación central de la tradición socialista. Sin embargo, a diferencia de esta última, se agrega que la eficacia de los derechos sociales depende de su vínculo indisoluble con los derechos civiles y políticos.

Palabras clave: Orden jurídico, derechos sociales, justicia, igualdad, Estado social de derecho.
\end{abstract}

\author{
En efecto, la distribución de la riqueza \\ es producto del orden legal: \\ la riqueza de un ciudadano \\ depende enormemente \\ delas leyes que haya promulgado su común. \\ RONALD DWORKIN
}

\footnotetext{
* Doctor en Filosofía, Universidad de Constanza, Alemania. Profesor-investigador del Departamento de Filosofía en la Universidad Autónoma M etropolitana (UAM)-Iztapalapa. Correo electrónico: eserranog@axtel.net
}

Volumen 8, número 15, enero-abril, 2011, pp. 189-214 
En numerosas ocasiones se menciona el ordenamiento jurídico mexicano como ejemplo de una de las primeras constituciones en las que se consagran los derechos sociales. En efecto, en el documento constitucional de 1917, emanado de la Revolución mexicana, se plasman las demandas más importantes de los diversos grupos que habían participado en ella. Podemos mencionar el artículo 123, donde se consagra el derecho al trabajo o el artículo 27, en el cual se declara a la Nación como propietaria originaria de las tierras y de las aguas, lo cual, posteriormente, permitió sustentar legalmente una amplia reforma agraria. Si bien estos derechos han tenido una importante repercusión en la vida social y política, no se puede decir que se han realizado las aspiraciones que en ellos se encuentran. Basta recordar que México es uno de los países en los que existe una mayor concentración de la riqueza y que una proporción significativa de su población se encuentra sumida en la miseria.

De hecho, el caso mexicano es utilizado frecuentemente para sustentar los argumentos de aquellos que niegan la posibilidad de caracterizar a los derechos sociales como fundamentales. Gran parte de estos argumentos consiste en sustentar que existe una diferencia cualitativa entre los derechos fundamentales clásicos o liberales y los derechos sociales. Según esto, mientras los primeros establecen una serie de restricciones al ejercicio del poder político, para garantizar la libertad individual, los derechos sociales exigen una prestación positiva del Estado, cuyo cumplimiento trasciende la capacidad del sistema jurídico. Muchas veces se agrega la tesis en la cual se afirma la imposibilidad de mantener la tutela jurídica de los derechos sociales debido a la imprecisión de su contenido. ¿Cuál es, por ejemplo, el contenido preciso de un derecho fundamental al trabajo digno y socialmente útil? Algunos teóricos llegan a considerar que esa supuesta imposibilidad de garantizar de manera efectiva los derechos sociales implica que ellos simplemente expresan objetivos o aspiraciones de la sociedad; pero que, en realidad, no pueden ser considerados derechos en sentido estricto.

En este trabajo me propongo realizar una defensa del carácter fundamental de los derechos sociales interna al sistema jurídico. En primer lugar, voy a cuestionar la descripción de los derechos fundamentales como un simple conjunto de normas que tienen o deben 
tener una misma forma. En contraste con esta descripción, considero que los derechos fundamentales conforman un sistema complejo, cuya unidad remite a un núcleo, constituido por la exigencia de garantizar la distribución justa de las condiciones que permiten el ejercicio de la libertad. Las diferencias formales que encontramos entre las normas que conforman ese sistema representan, precisamente, la dinámica que conduce a la realización de dicha exigencia. Hablo de una defensa interna porque quiero hacer patente que el sistema de los derechos fundamentales no es un agregado contingente de los diferentes ordenamientos jurídicos, sino un elemento ligado a su sentido social.

Posteriormente, se sustentará la tesis en la cual se afirma que la falta de eficacia de los derechos sociales en México no se puede atribuir a una anomalía de estos últimos, sino que ello se debe a una trasgresión del orden lexicográfico que constituye el sistema de los derechos fundamentales. Esto representa un síntoma de la persistencia de formas de dominación tradicionales, que han logrado mantener un amplio haz de privilegios, detrás de la fachada de un Estado constitucional; fenómeno que no es exclusivo de México, sino que se trata de un rasgo presente en gran parte de las sociedades latinoamericanas.

\section{LA AUTORIDAD DEL DERECHO}

En sus primeros momentos, el positivismo jurídico consideró que era posible describir el ordenamiento jurídico a partir de la noción de órdenes respaldadas en la amenaza de coacción. En contra de esta tesis, Hans Kelsen advirtió que si bien la coacción es un elemento distintivo del derecho, no es suficiente para explicar su dinámica. El derecho, a diferencia de las órdenes de un bandido, presupone el mandato de alguien autorizado y esa autoridad sólo puede provenir de una norma válida. De ahí que, para este autor, descifrar el enigma de la validez era una condición necesaria para dar cuenta de la autoridad propia del derecho $y$, de esta manera, acceder a una descripción adecuada de él. Como es sabido, en la Teoría pura del derecho, el término validez designa la existencia específica de una norma, esto es, afirmar que una norma es 
válida significa que existe. Por otra parte, en contraste con el iusnaturalismo, en dicha teoría se agrega que esa validez no puede ser un atributo que trascienda la voluntad de los seres humanos, pues el derecho es un artificio social. Como diría Carl Schmitt: Para que algo valga, alguien lo tiene que hacer valer.

Sin embargo, a diferencia de Schmitt, Kelsen sostiene que la validez no puede emanar de la decisión de un individuo, pues, ello implicaría que la norma carece de un sentido objetivo, es decir, que sólo expresaría los deseos de un individuo, lo cual nos conduce de nuevo al modelo simple de un bandido que sustenta sus órdenes en una amenaza de coacción. Recordemos que para Kelsen el concepto de norma presupone un estándar que es aceptado en la práctica social; en términos actuales se podría decir que para Kelsen la validez de una norma remite a la dimensión intersubjetiva. Precisamente, el adjetivo de pureza, con el cual califica a su teoría, implica que el fundamento de validez de una norma sólo puede encontrarse en otra norma, a la cual, metafóricamente, se le califica como norma superior en relación con la primera. De esta manera, arribamos a lo que se ha denominado cadena de validez, la cual define la jerarquía propia del ordenamiento jurídico. De acuerdo con Kelsen, para evitar el regreso al infinito de la cadena de validez es necesario presuponer la existencia de una norma fundamental (Grundnorm), que representa la fuente de validez (existencia) de todas las normas que pertenecen a un ordenamiento jurídico.

El hecho de que alguien ordene algo no es fundamento para considerar a la orden como válida, es decir, como una norma que obligue al sujeto al que la norma se dirige [... ]. Como se indicó, la norma que representa el fundamento de validez de otra norma es, en su respecto, una norma superior; pero la búsqueda del fundamento de validez de una norma no puede proseguir hasta el infinito, como la búsqueda por lacausa deun efecto. Tieneque concluir en una norma que supondremos la última, la suprema. Como norma superior tiene que ser presupuesta, dado que no puede ser impuesta por una autoridad cuya 
competencia tendría que basarse en una norma superior (Kelsen, 1986: 202). ${ }^{1}$

Para comprender con precisión la noción de norma fundamental hay que tomar en cuenta que es el resultado de un argumento trascendental. Esta modalidad de argumento se encuentra constituido, básicamente por dos premisas: en la primera se afirma, apoyándose en la experiencia, que cierto fenómeno existe y en la segunda se establece que de no darse un conjunto de condiciones ese fenómeno no podría existir. ${ }^{2} \mathrm{~A}$ partir de ello se concluye la existencia de esas condiciones. Aquello que asume Kelsen como verdadero es, simplemente, el uso social del derecho como medio para regular las relaciones sociales. En la medida en que la validez representa la forma específica de existencia de una norma, y que validez de una norma sólo puede encontrarse en otra norma, se concluye que esa norma fundamental debe existir.

Considero que utilizar el recurso de un argumento trascendental, ante el problema de la validez, representa una aportación muy ingeniosa deKelsen, que nos sitúa en un sendero reflexivo fructífero. Sin embargo, hay que reconocer que este autor no avanza lo suficiente por dicho sendero 0 , por lo menos, no con la suficiente claridad, para decir que se arribó a una solución del problema de la validez. Prueba de ello es la amplia polémica que suscitó la noción de norma fundamental. Me parece que para superar las confusiones que han predominado en esta polémica es menester ir más allá de la Teoría Pura. No es suficiente decir que la norma fundamental es un presupuesto necesario, se requiere, además, hacer explícito lo que ese presupuesto implica.

En la medida que la norma fundamental, en tanto fundamento de validez de las normas positivas, no se puede derivar de los hechos (de una descripción del ser), ni puede provenir del arbitrio de un soberano, sólo queda como alternativa, racionalmente aceptable, reconocer que la norma fundamental remite a una práctica colectiva. En cierta manera,

\footnotetext{
1 "Todas las normas cuya validez pueda remitirse a una misma norma fundamental, constituyen un sistema de normas, un orden normativo" (Kelsen, 1986: 202).

2 Para analizar el al cance y límites de los argumentos trascendentales remito a la antología compilada por Isabel Cabrera (1999).
} 
esto es lo que plantea de manera implícita Kelsen al afirmar que la eficacia del derecho es una condición necesaria de la validez. Ello no quiere decir, como afirman $\mathrm{H}$ art y Bobbio, que la validez se reduce en última instancia a la eficacia. La tesis es que la eficacia es un síntoma (la ratio cognoscendi) de la existencia de esa norma. De esta manera se plantea que la eficacia del derecho no sólo depende de la amenaza de coacción, sino que también es una consecuencia de la autoridad con la que se presenta en las relaciones sociales, es decir, de que un porcentaje socialmente relevante de los participantes reconozcan la validez del derecho.

Para comprender la creencia social en la validez de la norma fundamental se tiene que tomar en cuenta su contenido, el cual, según el propio Kelsen, puede expresarse de la siguiente manera: D ebes obedecer a la Constitución y, por tanto, a todas las leyes que se han promulgado de acuerdo con lo que ella establece. Pero esta formulación resulta incompleta, ya que, desde la perspectiva del participante (aquello que Hart denomina el punto de vista interno), de inmediato cabe preguntar: ¿por qué obedecer a la Constitución es un deber? Como hemos apuntado, el propio Kelsen admite que la obediencia al derecho sólo puede adquirir el carácter de un deber, cuando no se reduce a ser la orden de un individuo o grupo particular. Para responder a esta pregunta se requiere introducir otro argumento trascendental en el cual se sostiene que la existencia de un deber (en un sentido estrictamente normativo) implica reconocer la libertad de aquellos a los que se exige obediencia. Dicho de otra manera, sólo pueden tener un deber aquellos a quienes se les puede imputar sus acciones. Por tanto el deber de obedecer a la Constitución sólo puede justificarse, en términos racionales, cuando esa misma constitución garantiza el derecho a la libertad. Esto había sido planteado ya por Kant en su M etafísica de las costumbres: "La libertad (la independencia con respecto al arbitrio constrictivo de otro), en la medida que puede coexistir con la libertad de cualquier otro según una ley universal, es este derecho único, originario, que corresponde a todo ser humano en virtud de su humanidad" (Kant, 1989: 47). ${ }^{3}$

\footnotetext{
${ }^{3}$ Esto corresponde a la caracterización kantiana del derecho como el conjunto de condiciones bajo las cuales el arbitrio de uno puede conciliarse con el arbitrio del otro, según una ley universal.
} 
Calificar la garantía de las condiciones que permiten el ejercicio igualitario de la libertad como un derecho originario, no significa que este sea un elemento natural o trascendente respecto al orden civil de la sociedad. Dicho derecho, como cualquier otro, es un artificio social; pero representa la condición necesaria del juego inherente al ordenamiento jurídico. La justificación normativa de que una acción sea punible es que esa acción sea imputable al sujeto, esto es, que se le reconozca a este último como un ser libre. Por tanto es posible afirmar que el derecho a la libertad se encuentra ligado de manera indisoluble al sentido social del derecho.

Es evidente que Kelsen no aceptaría la tesis de que la norma fundamental implica la exigencia de garantizar la libertad de todos los participantes. Según él, ello significaría traicionar la pretensión científica de ofrecer una descripción de la multiplicidad de los sistemas jurídicos tal y como son y no como deberían ser. A ello hay que responder que si se asume al derecho como un artificio humano, entonces se requiere aceptar que la descripción del derecho, como la de cualquier otro artefacto, presupone la comprensión de su sentido social. ${ }^{4}$ Lo que encontramos en las descripciones empíricas es que no todo ordenamiento jurídico cumple o se adecua a su sentido social. Pero, así como la inadecuación entre el ordenamiento jurídico y su sentido social no implica, en contra de lo que sostenía el iusnaturalismo, que el primero pierda su carácter de derecho; tampoco esa inadecuación presupone que se pierda el sentido social del derecho. Por el contrario, la disonancia entre el sentido social del derecho (lo que el derecho debe ser) y su realidad (lo que el derecho es) representa un aspecto esencial de la dinámica del sistema jurídico y, como tal, tiene que ser tomada en cuenta por la teoría.

El propio Kelsen ofrece una explicación del origen de esa inadecuación entre el sentido social del derecho, como instancia que debe garantizar la distribución justa de las condiciones que permiten el ejercicio de la libertad, y su realidad en los diferentes contextos sociales. Ello sucede cuando introduce la importante distinción entre sistemas

${ }^{4}$ Como diría Gustav Radbruch (2005: 47): “El concepto de derecho (lo queel derecho es en los diversos contextos sociales), se orienta por la idea del derecho (lo que el derecho deber ser), lo cual implica que la segunda precede lógicamente al primero". 
normativos estáticos y sistemas normativos dinámicos. Un sistema normativo estático es aquél en el que la norma superior determina, por derivación lógica, el contenido de las normas inferiores. El iusnaturalismo pensaba que el sistema jurídico tenía esta forma; por ello, consideraba que la justicia inherente a la norma básica tenía que trasmitirse, de manera necesaria, al resto de las normas. En cambio, Kelsen mantiene que el orden jurídico tiene un carácter dinámico; por lo cual la pretensión de justicia de la norma fundamental no determina a priori el contenido de las normas inferiores. La norma fundamental contiene un hecho productor de normas, esto es, otorga facultades a una autoridad que determina cómo deben producirse las normas generales e individuales del ordenamiento jurídico.

El sistema normativo que aparece como un orden jurídico, tiene esencialmente un carácter dinámico. Una norma jurídica no vale por tener un contenido determinado; es decir, no vale porque su contenido pueda inferirse, mediante un argumento deductivo, de una norma fundamental presupuesta, sino por haber sido producida de determinada manera, y, en última instancia, por haber sido producida de la manera determinada por una norma fundamental (Kelsen, 1986: 205).

Por tanto, la exigencia de garantizar el ejercicio generalizado de la libertad, presupuesta en la norma fundamental, no tiene que realizarse de manera necesaria en las normas positivas. Por el contrario, el carácter formal, procedimental, de la unidad del derecho significa que, si no existe un control real de aquellos que detentan el poder y, con él, la facultad de establecer normas, es altamente probable que se genere una inadecuación entre normas de ese ordenamiento jurídico particular y el sentido social del derecho. El efecto de la falta de adecuación entre un ordenamiento jurídico particular y el sentido social del derecho no es, por supuesto, la pérdida de la vigencia del primero. De hecho, nunca se accede a una plena adecuación entre lo que es y lo que deber ser el derecho. Sin embargo, cuando no existe un cierto vínculo entreambas dimensiones, esto es, cuando el derecho no garantiza un cierto grado de libertad, lo que pierde es su autoridad; lo cual se traduce, a mediano y largo plazo, en una pérdida significativa de su eficacia. Me parece que esto es lo que sucede en diversas sociedades latinoamericanas. En contraste con ello, los estados constitucionales de 
derecho tienen como primer objetivo mantener el nexo entre el sentido social del derecho y su realidad institucional.

\section{LA DESCRIPCIÓN DE LOS DERECHOS FUNDAMENTALES}

En el apartado anterior he buscado sustentar la tesis respecto a que la norma fundamental, en la cual se sustenta la validez del ordenamiento jurídico, implica la exigencia de garantizar la libertad (la obediencia a la legalidad sólo puede ser un deber cuando reconoce a los individuos como seres libres). Aunque ello no quiere decir que las normas positivas, de los distintos ordenamientos jurídicos particulares, garanticen necesariamente esa libertad. Ahora bien, la garantía a la libertad es un principio abstracto, que debe concretarse en una diversidad de normas (principios y reglas). Precisamente, los derechos fundamentales representan la positivación y, con ella, la determinación específica de dicha exigencia inherente a la norma fundamental. Según esto, los derechos fundamentales no pueden describirse como un simple conjunto de normas que tienen o deben tener una misma forma, sino que configuran un sistema que tiene como núcleo el principio de garantizar la libertad y un entramado de normas, cuya forma y contenido concreto varía en los distintos contextos sociales. La primera ventaja que ofrece esta descripción consiste en hacer patente que resulta compatible afirmar la universalidad de los derechos fundamentales y, al mismo tiempo, asumir su carácter histórico.

Cuando se afirma la universalidad de los derechos fundamentales nos estamos refiriendo al núcleo de ese sistema, como elemento constitutivo del sentido social del derecho. En cambio, al hablar de las variaciones de los derechos fundamentales se destaca el entramado de normas que rodea a ese núcleo, el cual denota los diferentes caminos que históricamente se han seguido para realizar las condiciones que permiten el ejercicio de la libertad en las distintas sociedades. Creo que se puede explicar esta idea mediante un ejemplo relativamente sencillo. En la segunda enmienda de la Constitución de los Estados U nidos de N orteamérica se establece lo siguiente: Siendo necesaria una milicia bien ordenada para la seguridad de un Estado libre, no se violará el derecho 
del pueblo a poseer y portar armas. El hecho de que las milicias de coIonos resistieran con éxito los abusos del Estado inglés, indujo a los constitucionalistas norteamericanos a considerar que un buen medio para garantizar la libertad individual, ante los potenciales riesgos de un gobierno central, era otorgar a los ciudadanos el derecho a portar armas, para formar milicias capaces de oponerse al ejército profesional del Estado.

Pero eso no quiere decir que esa norma sea válida para todos los contextos sociales. Incluso, me parece que la creencia en que el derecho a portar armas para formar milicias, representa un buen medio para garantizar la libertad en la propia sociedad norteamericana de nuestros días, puede ser criticada. Se trata de una crítica técnica, es decir, se pone en tela de juicio el considerar a esa segunda enmienda como un medio eficaz para acceder a un fin. Lo que no se pone en cuestión en dicha crítica es el fin, esto es, la exigencia de garantizar la libertad de los ciudadanos. Para mencionar una alternativa, pensemos que en otras sociedades se ha considerado que la defensa de la libertad se ve mejor servida a través de un sistema de corporaciones autónomas, las cuales puedan incidir en el proceso legislativo. Sin embargo, ahora no me interesa adentrarme en esta polémica, sino únicamente destacar que el reconocimiento de los derechos fundamentales como elementos surgidos de una larga historia de luchas sociales y cuyo contenido específico es variable, no presupone negar su pretensión de validez universal.

La descripción de los derechos fundamentales como un sistema conformado por un núcleo constante y una armazón de normas cambiantes la encontramos ya en la teoría de Kant, cuando afirma que la libertad debe considerarse como una idea de la razón que requiere realizarse a través de las acciones de los seres humanos:

Una constitución que promueva la mayor libertad humana de acuerdo con leyes que hagan que la libertad de cada uno sea compatible con la de los demás (no una constitución que promueva la felicidad, pues ésta se seguirá por sí sola), es, como mínimo, una idea necesaria, que ha de servir de base, no sólo al proyecto de una constitución política, sino a todas las leyes. Para ello debe hacerse abstracción 
desde el comienzo, de los obstáculos actuales, que acaso no provengan inevitablemente de la naturaleza humana, sino más bien del descuido de las ideas auténticas en la legislación. [... ] Aunque esto no llegue a producirse nun$\mathrm{ca}$, la idea que presenta ese maximum como arquetipo es plenamente adecuada para aproximar progresivamente la constitución jurídica de los hombres a la mayor perfección posible. En efecto, nadie puede ni debe determinar cuál es el supremo grado en el cual tiene que detenerse la humanidad, ni, por tanto, cuál es la distancia que necesariamente separa la idea y su realización. N adie puede ni debe hacerlo porque se trata precisamente de la libertad, la cual es capaz de franquear toda frontera predeterminada (Kant, 1984: 311-312 [A316-317/B373-374]. Cursivas de Kant). ${ }^{5}$

Pero asumir la pluralidad de formulaciones de los derechos fundamentales, lo cual expresa la diversidad cultural, no significa que todas ellas puedan considerarse aceptables. Cuando un representante del Estado chino ante el Comité de Derechos Humanos de la Organización de las Naciones Unidas (onu) afirma, como respuesta a la crítica de sus colegas occidentales, que existe una formulación de esos derechos propia de su cultura, tendríamos, en principio, que darle la razón. Pero, ante la represión sangrienta en la Plaza de Tian'anmen, es necesario agregar que esa concepción china de los derechos fundamentales no tiene vigencia en esa sociedad. Esto es, las distintas versiones de los derechos fundamentales tienen que cumplir con ciertos requisitos básicos, lo cual indica que el sistema de los derechos también presupone un cierto orden, el cual es un elemento indispensable para enfrentar las tensiones y conflictos que surgen, de manera ineludible, entre las diversas normas de ese sistema.

Sobre este tema Kant nos ofrece una primera pista cuando, en su polémica con el gobierno prusiano, sostienequela libertad de expresión

\footnotetext{
${ }^{5}$ Sobre el tema de la distinción entre reglas y principios y la definición de estos últimos como mandatos de optimización consultar Alexy (1997), en especial el capítulo tercero: "La estructura de las normas de derecho fundamental".
} 
es la primera norma que debe estar presente en un catálogo de los derechos fundamentales. Ello se debe a que esta modalidad de libertad es la que permite introducir el principio de la equidad, entendido en su sentido clásico, esto es, la corrección de la legalidad, ante la experiencia de los múltiples casos concretos. ${ }^{6}$ Sin embargo, para adentrarnos en la reflexión sobre el orden que conforma el sistema de los derechos fundamentales podemos acudir a la conocida clasificación que propone T. H. Marshall, en la que se distingue entre derechos civiles, políticos y sociales.

Según este autor dicha distinción no la impone la lógica, sino la historia, pues los derechos civiles se consolidaron en el siglo XVIII, los derechos políticos en el XIX y los sociales en el XX. Si bien esto corresponde, hasta cierto punto, a la historia de la Gran Bretaña, los Estados Unidos y los países escandinavos, no se adecua al proceso histórico de otras naciones. Por ejemplo, en Alemania el reconocimiento estatal de los derechos sociales precedió a los derechos políticos. Ello se debe a que el canciller Bismark utilizó los derechos sociales para negar a los ciudadanos, en especial a la clase obrera, sus derechos políticos. Algo parecido había sucedido en Francia durante el Imperio napoleónico. La clasificación de Marshall no es capaz de aproximarnos a la complejidad del desenvolvimiento histórico de los derechos sociales en las distintas sociedades. Lo que sí otorga es, para decirlo en términos de Rawls, un orden lexicográfico, indispensable para afrontar las tensiones y conflictos que surgen entre las normas que conforman el sistema. Dicho de otra manera, al contrario de lo que sostiene Marshall, no es la historia, sino la lógica la que impone ese orden.

En primer lugar, me parece evidente que la consolidación de los derechos políticos presupone lógicamentela plena vigencia de los derechos civiles. Por ejemplo, el derecho a votar y ser votado, elemento central de los derechos políticos, pierde su sentido si se carece de los derechos que garantizan la libertad individual. Recordemos que en los regímenes social istas existían procesos electorales, pero la ausencia de derechos

${ }^{6}$ Desde Aristóteles se ha establecido que la legalidad sól o puede mantener su pretensión dejusticia si es complementada por el principio de equidad. 
civiles, impedían una auténtica competencia, transformando a dichos procesos en una simple mascarada de los gobiernos autoritarios. Si bien las elecciones representan el rasgo distintivo de los sistemas democráticos, su éxito, es decir, su adecuado funcionamiento en términos de la normatividad democrática, requiere una serie de condiciones. La primera de ellas es la garantía efectiva de los derechos civiles.

Por otra parte, los derechos sociales presuponen la existencia de derechos civiles y políticos. Quizá este nivel del orden lexicográfico no resulte evidente; de hecho, parece contradecir al Ilamado sentido común, para el cual la posesión de un cierto nivel de bienes representa un requisito para el ejercicio de la libertad. Sin embargo, la aparente solidez de esta creencia se desvanece en cuanto nos adentramos en el complejo problema de la justicia distributiva. A pesar de las distintas posturas que encontramos en esta amplia polémica, existe un amplio acuerdo respecto a que no es posible acceder a una fórmula que nos permita ofrecer una solución concreta a este problema. Por eso, desde el republicanismo clásico (Aristóteles), hasta nuestros días (Rawls), se ha planteado que, ante la imposibilidad de reducir la distribución justa a un asunto exclusivamente técnico, la única alternativa consiste en introducir criterios distributivos que sean determinados a través de la participación de los diferentes grupos sociales. Criterios que, además, deben corregirse o transformarse de acuerdo con las cambiantes circunstancias sociales. Ello implica que los derechos civiles y políticos son una condición necesaria, aunque no suficiente, para consolidar y mantener la eficacia de los derechos sociales.

Para comprender con precisión el sentido del orden lexicográfico propio de los derechos fundamentales, es preciso subrayar que no tiene un carácter histórico, es decir, que no es posible pensar el desarrollo del sistema de los derechos fundamentales como una simple sucesión que conduzca de los Ilamados derechos de primera generación (civiles) a los de tercera generación (sociales). Desde una perspectiva genética, ese desarrollo es variable, de acuerdo con las diferencias existentes en los distintos contextos sociales. El orden lexicográfico de los derechos fundamentales, tiene un carácter lógico y, como tal, se erige en un elemento normativo para juzgar los múltiples ordenamientos jurídicos, 
en términos de la realización de la exigencia de libertad (se debe advertir que la lógica no coincide necesariamente con el desenvolvimiento histórico). Además, el orden lexicográfico funciona como una variable central para determinar el peso de cada derecho en los conflictos que surgen de manera inevitable entre las normas que componen el sistema de los derechos fundamentales; esto es, el orden lexicográfico es un elemento indispensable en la ponderación de los derechos ante la necesidad de aplicarlos a los casos concretos.

Es importante subrayar que el orden lexicográfico del sistema de los derechos fundamentales no implica una jerarquía que pueda interpretarse en términos de mayor o menor importancia. Los tres tipos de derechos son indispensables para la realización de la exigencia de libertad, ligada a la pretensión de validez propia del ordenamiento jurídico. La descripción de los derechos fundamentales como un sistema que se desarrolla históricamente, presupone que derechos civiles, políticos y sociales conforman una unidad indisoluble. Precisamente, como se verá en el próximo apartado, dicha descripción es la que ofrece la estrategia adecuada para enfrentar con éxito las críticas que se dirigen contra la inclusión de los derechos sociales en el catalogo de los derechos fundamentales.

\section{LA DEFENSA DE LOS DERECHOS SOCIALES}

Gran parte de las críticas a la inclusión de los derechos sociales en el catálogo de los derechos fundamentales toma como punto de partida la existencia de una diferencia estructural entre estos y los derechos fundamentales clásicos o liberales. Así, por ejemplo, Carl Schmitt sostiene que los derechos fundamentales auténticos pertenecen al ser humano con independencia del Estado; en cambio, Ios derechos sociales presuponen la pertenencia de un individuo a un orden civil particular y su variable capacidad de ofrecer prestaciones.

A su vez, tienen distinta estructura los derechos, esencialmente socialistas, del individuo a prestaciones positivas del Estado. No pueden ser ilimitados, pues todo derecho 
a prestaciones ajenas es limitado, pero lo sería en cualquier caso un derecho de todos a prestaciones del Estado. Tales derechos presuponen una organización social a la que se incorpora el individuo titular del derecho. Con eso, su derecho se relativiza ya. [... ] Cuando una ley constitucional proclama el "derecho al trabajo", no puede pensarse con ello en un derecho ilimitado en principio. [... ] Según su estructura lógica y jurídica, tal derecho se encuentra en contraposición con los auténticos derechos fundamentales y de libertad, siendo por eso erróneo el hablar indistintamente de "derechos fundamentales" (Schmitt, 1982: 174. Cursivas de Schmitt).

Frente a esto hay que responder que aunque gran parte de los derechos civiles hacen referencia al individuo, con independencia al orden civil de la sociedad, su vigencia presupone necesariamente la presencia de este último. Además, los derechos políticos, los cuales han sido reconocidos como parte esencial de los derechos fundamentales, también presuponen la pertenencia al orden civil de la sociedad. En la crítica de Schmitt resulta más importante la distinción entre derechos a acciones negativas (omisiones) y los que exigen acciones positivas (prestaciones), pues se trata de un elemento que no puede negarse. Sin embargo, ella no coincide con la diferenciación entre derechos fundamentales clásicos y derechos sociales, porque diversos derechos civiles y políticos también requieren prestaciones estatales. La garantía de la seguridad individual, por ejemplo, requiere de inversiones cuantiosas por parte del Estado; así mismo, la libertad de expresión o el derecho al voto también exigen importantes recursos. Por tanto, no se puede hablar de una ruptura entre las diferentes modalidades de los derechos fundamentales.

El presupuesto que ocasiona las confusiones en este punto es la creencia, propia del iusnaturalismo tradicional, de que existen derechos que trascienden el orden civil de la sociedad y que, como tales, son absolutos. Creencia que retoma Schmitt en su objetivo de cuestionar la concepción liberal. Pero la descripción que se ha esbozado en este trabajo de los derechos fundamentales se ha mantenido alejada del 
dilema fatal configurado por las posiciones del iusnaturalismo y el positivismo. Aunque existen derechos fundamentales que se otorgan a los individuos con independencia de su pertenencia al orden civil, esto es, de su ciudadanía en sentido estricto, ellos también son un artificio social, y como tales, también requieren del reconocimiento y compromiso activo de ese orden.

En relación con la diferencia estructural entre los denominados derechos fundamentales clásicos y los derechos sociales, otras críticas apuntan que mientras los primeros son universales (corresponden a todos los miembros de la sociedad), gran parte de los segundos están ligados a un cuantificador particular, esto es, se otorgan a grupos específicos de la sociedad (mujeres, trabajadores, minorías culturales, etcétera). La aparente fuerza de este tipo de críticas proviene del supuesto no justificado de que la unidad de los derechos fundamentales se encuentra en su estructura semejante. Pero esa fuerza desaparece en cuanto tomamos en cuenta que los derechos fundamentales constituyen un sistema que se desarrolla históricamente.

Cuando alguien sostiene que los derechos fundamentales sólo están constituidos por normas universales asume, de manera implícita o explícita, que las condiciones de una distribución igualitaria de la libertad ya existen o ya han existido. Según esto las diferencias que encontramos en las sociedades sólo pueden ser consideradas como el resultado de las decisiones individuales y, por tanto, no pueden ser consideradas como injustas. Pero la idea de una igualdad originaria que marca el punto cero del proceso distributivo carece por completo de un sustento empírico. Por el contrario, la distribución igualitaria de las condiciones que hacen posible el ejercicio generalizado de la libertad representa una meta que requiere alcanzarse en el futuro. De ahí que el desarrollo del sistema de los derechos universales se mueva en un proceso de especificación, desde normas universales a normas particulares. En un primer momento, mediante las normas universales se cuestionan el sistema de privilegios propios de las sociedades tradicionales, para dirigirse, posteriormente, mediante normas particulares a enfrentar las distintas formas de dominación que afectan a los diversos grupos sociales. ${ }^{7}$

\footnotetext{
${ }^{7}$ Aquí cabe aclarar lo siguiente: la diferencia entre los privilegi os y los derechos consiste en quelos primeros son particulares, mientras que los segundos son generales. Sin embargo,
} 
Universalidad y particularidad no son excluyentes en el interior del sistema de los derechos fundamentales, ya que representan los extremos entre los que este sistema se desarrolla. La universalidad significa la inclusión de las diferencias en la unidad del orden civil de la sociedad; pero, la realización concreta de la igualdad requiere de normas particulares que, como tales, sean sensibles a la situación específica en la que se encuentran los grupos sociales. Con ello se plantea que la defensa de la particularidad requiere, de manera, necesaria, la referencia a un principio universalista.

O tra crítica que se dirige a los derechos sociales consiste en afirmar que no son justiciables o lo son en una medida reducida. ${ }^{8}$ Las razones que se esgrimen para sustentar esta afirmación son las siguientes: 1) el contenido de los derechos sociales no es preciso; 2) no pueden ser reivindicados frente a un sujeto determinado, y 3 ) la realización de esta modalidad de derechos trasciende la capacidad del sistema jurídico, incluso del propio Estado. En efecto, el que se plasmen las demandas de los grupos sociales en la Constitución, como sucedió en México después de la Revolución, no significa que ellas se conviertan en derechos en sentido estricto. Para lograr esto se requiere, además, de una diversidad de normas secundarias que precisen tanto su contenido, como los mecanismos para garantizar su protección efectiva. De lo contrario es mera retórica 0 , en el mejor de los casos, una simple expresión de buenos deseos. Pero esta exigencia no es exclusiva de los derechos sociales, sino que se trata de un rasgo común a todos los derechos fundamentales.

Por otra parte, en relación con la tercera razón que se ha señalado, hay que reconocer que la plena realización de gran parte de los derechos sociales sí es una tarea que trasciende la facultad del sistema jurídico, ya que depende del desarrollo de la capacidad productiva de la sociedad. Sin embargo, sí es posible establecer porcentajes de los recursos que

el incorporar normas particulares en el sistema de los derechos fundamentales se justifica en la medida en que ell as si empre se encuentran subordinadas a normas universales.

8 "Son verdaderos derechos aquellos que satisfacen conjuntamente tres condiciones: son susceptibles detutelajurisdiccional (son justiciables); pueden ser ejercitad os o reivindicados frente a un sujeto determinado, y su contenido consiste en una obligación de conducta bien definida, al igual que el sujeto que era su titular" (Guastini, 2001: 221). 
deben dirigirse a la realización de los derechos sociales. Si bien esto establece límites a la competencia presupuestaria del Poder Legislativo, hay que destacar que el peso de los derechos individuales debe ser mayor que las razones políticas. Aunque no podemos adentrarnos ahora al complejo campo problemático de la tutela jurídica o justiciabilidad de los derechos sociales, lo que hace patente dicho tema es que la eficacia de los derechos sociales depende, como se ha establecido, del ejercicio generalizado de los derechos civiles y políticos, ya que es esto lo que genera la presión social necesaria para crear los medios indispensables para transformarlos en auténticos derechos.

\section{¿DERECHOS SOCIALES SIN ORDEN CIVIL?}

Como se puede apreciar, la estrategia que propongo para defender la inclusión de los derechos sociales en el catálogo de los derechos fundamentales consiste, básicamente, en afirmar que ellos son un requisito indispensable en la realización de la libertad, y que, a su vez, este último objetivo es una exigencia inherente al sentido social del derecho. Por supuesto que esto no es ninguna novedad; se trata de la estrategia argumentativa que se ha utilizado, por lo menos, desde la Revolución francesa por parte de los jacobinos y que, posteriormente, retomó la tradición socialista. Sin embargo, también he planteado que dicha estrategia sólo funciona si se mantiene unida al orden lexicográfico propio de los derechos fundamentales. El olvidar esto ha tenido fatales consecuencias en la práctica política. Con el objetivo de explicar esta tesis voy a empezar por citar un fragmento de un discurso de Robespierre de 1793.

¿Cuál es el primer fin de la sociedad? Mantener los derechos imprescriptibles del ser humano. ¿Cuál es el primero de esos derechos? El de existir. La primera ley social es, pues, la que asegura a todos los miembros de la sociedad los medios de existir; todas las demás se subordinan a ésta; la propiedad no ha sido instituida, ni ha sido garantizada, sino para cimentar aquella ley; es por lo pronto 
para vivir que se tienen propiedades. $Y$ no es verdad que la propiedad pueda jamás estar en oposición con la subsistencia de los seres humanos (citado en Domenech, 2004: 82).

En contraste con las visiones maniqueas de la Revolución francesa hay que reconocer la contribución jacobina a la historia de los derechos fundamentales, que consiste, precisamente, en destacar que el derecho a la libertad se convierte en mero formalismo si se desliga de la demanda de justicia distributiva. Pero, al mismo tiempo, es menester advertir la ambigüedad de esta contribución, la cual reside en considerar que la enorme importancia de los derechos sociales justifica negar o posponer los derechos civiles y políticos, para facilitar la realización de los primeros. Justificación que presupone la posibilidad de reducir el problema de la justicia distributiva a un asunto técnico, cuya solución puede ser definida e implementada por un conjunto reducido de individuos que poseen cierta capacitación y buenas intenciones. Invertir el orden lexicográfico de los derechos fundamentales no abre el camino que conduce a la realización de los derechos sociales, únicamente ofrece una falsa legitimación a tiranías que dicen actuar en beneficio del pueblo.

Recordemos que al no existir un algoritmo que permita resolver el complejo problema de una distribución justa, los únicos criterios distributivos aceptables son aquellos que se determinan mediante la participación de todos los grupos sociales. Criterios que, además, no poseen a priori una garantía de validez, sino que tienen que ser corregidos continuamente de acuerdo con la experiencia. Ello presupone que la consolidación de los derechos sociales sólo puede realizarse en el interior de un orden civil que garantice la libertad de todos los participantes. La idea de que un pueblo sólo está en condiciones de ejercer la libertad cuando se han eliminado los restos de los sistemas de dominación tradicionales y cuando posea los recursos suficientes sólo ha servido como coartada para que las dictaduras comisariales se conviertan en dictaduras soberanas. ${ }^{9}$ La triste historia de las revoluciones

9 "Confieso que no puedo acomodarme a esta expresión de la que se sirven también hombres sensatos: cierto pueblo (en vías de elaborarse una libertad legal) no está maduro 
modernas ejemplifica esta situación. Sobre ello, Hannah Arendt sostiene que el fracaso de la mayoría de los procesos revolucionarios se debe a que en ellos se antepuso la solución de lo que ella llama la cuestión social, es decir, el tema de la justicia distributiva, a la constitución de un orden libre.

Cuando la Revolución abandonó la fundación de la libertad para dedicarse a la liberación de los seres humanos del sufrimiento, derribó las barreras de la resistencia y liberó, por así decirlo, las fuerzas devastadoras de la desgracia y la miseria. [... ] Ninguna revolución ha resuelto nunca la "cuestión social", ni ha liberado al ser humano de las exigencias de la necesidad, pero todas ellas, a excepción de la húngara de 1956, han seguido el ejemplo de la Revolución Francesa y han usado y abusado de las potentes fuerzas de la miseria y la indigencia en su lucha contra la tiranía y la opresión. Aunque toda la historia de las revoluciones del pasado demuestra sin lugar a dudas que todos los intentos realizados para resolver la cuestión social con medios políticos conduce al terror y que es el terror el que envía las revoluciones al cadalso, no puede negarse que resulta casi imposible evitar este error fatal cuando una revolución estalla en una situación de pobreza de las masas (Arendt, 1988: 112).

La primera premisa de la argumentación de Arendt consiste en afirmar que si bien la violencia revolucionaria puede servir a los individuos para liberarse de una tiranía, nunca podrá, por sí misma, conducir a la constitución de un orden civil que garantice el ejercicio de la libertad. De inmediato agrega que en un contexto social en el que predomina la desigualdad social y, con ella, la falta de un orden legal que sea percibido por la mayoría como una instancia revestida de autoridad, es altamente

para la libertad; los siervos de un propietario rural no están maduros para la libertad; y así también, los seres humanos, en general, no están maduros aún para la libertad de creencia. Según un supuesto tal, la libertad nunca tendrá lugar; pues no se puede madurar para ella si no se ha sido ya antes puesto en libertad" (Kant, 1981: 234). 
probable que el proceso revolucionario conduzca a un simple cambio de los personajes que detentan el poder o bien a una nueva forma de tiranía. A partir de estas dos premisas concluye que la actividad política no pude ofrecer una solución a lo que ella llama la cuestión social, esto es, el problema de la justicia distributiva.

Sin embargo, ello representa una conclusión apresurada, pues, si asumimos la tesis de la propia Arendt respecto a que el objetivo supremo (en términos normativos) de la práctica política es la constitución de un orden civil que garantice la libertad, entonces se debería afirmar que la realización de ese objetivo es una condición necesaria, aunque no suficiente, para enfrentar con éxito el reto de una distribución justa de la riqueza. Lo que no puede superar la injusticia distributiva es una política revolucionaria en la que se invierta el orden lexicográfico de los derechos fundamentales. La violencia revolucionaria no ofrece un atajo que conduzca a suprimir o, por lo menos, reducir la pobreza a largo plazo, ya que la plena vigencia de los derechos civiles y políticos, que ofrece un orden civil consolidado, representa un requisito indispensable para que los derechos sociales puedan tener eficacia. ${ }^{10}$

Tomando en cuenta esta corrección que se ha introducido a la conclusión de Arendt, hay que admitir que la Revolución mexicana se ajusta a su modelo. En sus inicios, el primer objetivo que se proponían los revolucionarios mexicanos era transformar el principio de organización del gobierno, mediantela introducción de un control democrático del poder político; recordemos su consigna: sufragio efectivo, no reelección. En el Plan de San Luis Potosí (1910) se afirmaba que el pueblo mexicano era apto para la democracia y que sus gobernantes no respondían a esas legítimas aspiraciones. Resulta interesante recordar la

\footnotetext{
${ }^{10}$ Me parece que esta es la intuición que subyace al desarrollo de la social-democracia, en oposición a la concepción socialista tradicional. De ahí que Gustav Radbruch (2003) afirmara que no se puede ser socialista, si no se asumen los valores centrales del liberalismo. Por otra parte, cabe recordar que ya en 1917, Max Weber, en su conferencia El socialismo (en Weber, 1991), advertía que los acontecimientos en Rusia no anunciaban el advenimiento de la dictadura del proletariado, sino la dictadura del funcionario, en la cual los trabajadores y los campesinos lejos de obtener una ventaja, se verían sometidos a una forma de control más implacable que la imperante en las sociedades capital istas.
} 
manera en que se describe la tiranía, a la cual, según este programa revolucionario, los mexicanos no estaban acostumbrados a sufrir, desde la conquista de su independencia:

Tanto el poder Legislativo como el Judicial están completamente supeditados al Ejecutivo; la división de los poderes, la soberanía de los Estados, la libertad de los Ayuntamientos y los derechos del ciudadano están escritos en nuestra Carta Magna; pero, de hecho, en México casi puede decirse que reina la Ley Marcial; la justicia, en vez, de impartir su protección al débil, sólo sirve para legalizar los despojos que comete el fuerte; los jueces, en vez de ser los representantes de la Justicia, son agentes del Ejecutivo, cuyos intereses sirven fielmente; las cámaras de la Unión no tienen otra voluntad que la del Dictador; los gobernadores de los Estados son designados por él y ellos, a su vez, designan e imponen de igual manera a las autoridades municipales (Plan de San Luis Potosí, en Garciadiego, 2003: 96-97).

Sin embargo, el grupo triunfante, el cual posteriormentefundó el partido hegemónico durante más de 70 años, hizo a un lado la exigencia de establecer una organización democrática del poder político. Su justificación se basaba, precisamente, en el discurso sobre la necesidad de realizar las aspiraciones inherentes a los derechos sociales, que se habían reconocido en la Constitución de 1917, antes de constituir un orden libre. Los movimientos campesinos, obreros y populares quedaron sometidos a un sistema corporativo estatal. Al desligarse los derechos sociales de los derechos civiles y políticos, los primeros se convirtieron en privilegios otorgados por la clase gobernante a los grupos particulares que se sometían, mediante cadenas clientelares, a la disciplina del partido gobernante.

Pero la Revolución no alteró la estructura básica de la relación entre gobernantes y gobernados. De hecho, gran parte de la descripción del Plan de San Luis que se ha citado puede utilizarse para caracterizar al régimen posrevolucionario. Lejos de instituirse un gobierno de las 
leyes, se mantuvo una variante del gobierno de los hombres, en la cual la legalidad se veía reducida, básicamente, a una fachada, mientras el poder continuaba circulando por la intrincada red de lealtades personales. La falta de eficacia de los derechos civiles y políticos impidió la realización de los objetivos establecidos por los derechos sociales. Después de un largo periodo de gobiernos revolucionarios no sólo se mantuvo el autoritarismo tradicional, sino que también la esperanza de alcanzar lo que se llamó justicia social permaneció como letra muerta en el texto constitucional.

En la actualidad se ha dado un importante proceso de liberalización en México, que ha permitido una división de los poderes y, con ella, la irrupción de la pluralidad. Incluso se han implementado procesos electorales competitivos que han dado lugar a una alternancia en el poder. Sin embargo, no se puede afirmar que se ha consolidado un sistema democrático, porque la fal ta de una infraestructura jurídica adecuada, que permita un efectivo control del ejercicio del poder político, ha impedido que la competencia política se torne funcional para el desarrollo social. Adam Smith (1993) advirtió que la competencia económica sin una regulación no da lugar al libre mercado, sino a la barbarie en la que se impone el más fuerte (un sistema de monopolios); de la misma manera podemos afirmar que la contienda electoral, sin una normatividad que sea asumida por todos los participantes como válida, no favorece la democratización. El propio Schumpeter que definía a la democracia por la presencia de procesos electorales competitivos, sostenía que el éxito de este proceso de decisión política dependía de una serie de condiciones, entre las que se encuentra la vigencia de los derechos civiles y políticos (Schumpeter, 1976).

El déficit más importante de la transición a la democracia en México se encuentra en el funcionamiento del poder judicial. Ello no podrá superarse con una simple reforma institucional, ya que se requiere también el desarrollo de una cultura política en la que se asuma la importancia del principio de la legalidad. El problema en relación con este punto es que la tradición autoritaria ha generado la percepción generalizada respecto a que la legalidad es un factor secundario, un mero elemento formal; incluso un número socialmente relevante de individuos la considera como un simple instrumento de dominio. Ello representa un 
síntoma de que la norma fundamental, mencionada al principio de este trabajo, no es un elemento aceptado en la práctica política. En efecto, resulta muy difícil convencer a los individuos de que tienen el deber de respetar la legalidad, si esta no ofrece una garantía efectiva de su integridad y libertad. El aspecto más negativo de la herencia autoritaria es la pérdida de la autoridad del derecho.

Es frecuente escuchar que la desigualdad representa el principal obstáculo a la consolidación de la democracia en México. Sin duda esto es cierto; desgraciadamente, no es tan frecuente encontrar que aquellos que afirman esto den el siguiente paso, el cual conduce a la siguiente pregunta: ¿cómo establecer criterios de justicia distributiva sin la presencia de un orden civil que garantice derechos civiles y políticos? La falta de una respuesta a esta interrogante saca a la luz el presupuesto que subyace a la ideología revolucionaria, a saber: la creencia en la posibilidad de acceder a una solución técnica al problema de la justicia distributiva y que sólo es necesario liberarse, de manera violenta, de las formas de dominación tradicionales, para que ella pueda implementarse. A pesar de que esa creencia ha sido criticada, por lo menos, desde Aristóteles, su persistencia se debe a que ella ofrece una coartada para legitimar gobiernos tiránicos, instrumentalizando el aspecto más ostensible y doloroso de la injusticia.

Sin duda la tradición socialista acierta cuando insiste en que la exigencia de libertad, implícita en los derechos fundamentales liberales, esto es, los derechos civiles y políticos, es un mero formalismo sin el complemento de los derechos sociales. Pero se equivoca al considerar que se pueden posponer o hacer a un lado los primeros, para allanar el camino que conduce a la realización de los segundos. Sólo dentro de un orden civil que garantice derechos civiles y políticos se puede consolidar el avance hacia una justicia distributiva. Como planteó Gustav Radbruch, en los años treinta del siglo pasado, no se puede ser un auténtico socialista, si no se asumen los principios básicos del liberalismo. 


\section{FUENTES CONSULTADAS}

Abramovich, V., Añon, M. J., y Courtis, C. (comps.) (2003), Derechos sociales. Instrucciones de uso, México: Fontamara.

Ackerman, B. (1993), La justicia social en el Estado liberal, Madrid: Centro de Estudios Constitucionales (CEC).

Alexy, R. (1997), Teoría de los derechos fundamentales, Madrid: CEC.

Arango, R. (2005), El concepto de derechos sociales fundamentales, Bogotá: Legis.

Arendt, H. (1988), Sobre la revolución, Madrid: Alianza.

BaldasarRe, A. (2001), Los derechos económicos, sociales y culturales, Bogotá: Universidad Externado de Colombia (UEC).

Cabrera Villoro, I. (comp.) (1999), Argumentos trascendentales, M éxico: Instituto de Investigaciones Filosóficas (IIF)-UNAM.

Carbonell M., Cruz Parcero, J. A. y Vázquez, R. (comps.) (2005), Derechos sociales y derechos de las minorías, 3a ed., M éxico: Porrúa/ UNAM.

DoméneCH, A. (2004), El eclipse de la fraternidad, Barcelona: Crítica.

Frankenberg, G. (1994), Auf der suche nach gerechten Gesellschaft, Frankfurt: Fischer.

Garciadiego Dantán, J. (2003), La Revolución mexicana. Crónicas, documentos, planes y testimonios, México: UNAM.

GuAstinI, R. (2001), Estudios de teoría constitucional, M éxico: Fontamara. HART, H. L. A. (1961), The concept of Law, Oxford: Clarendon Press.

Holzleithner, E. (2009), Gerechtigkeit, Stuttgart: Uni-Tascehnbücher (UTB) $\mathrm{GmbH}$.

Kant, I. (1984), Crítica de la razón pura, 3a ed., Madrid: Alfaguara. (1981), La religión dentro de los límites de la mera razón, Madrid: Alianza.

(1989), La metafísica de las costumbres, Madrid: Tecnos.

KeLSEN, H. (1986), Teoría pura del derecho, México: UnAM.

(1994), Teoría general de las normas, México: Trillas.

(1995), Teoría general del derecho y del Estado, México: UNAM.

Radbruch, G. (2003), Rechtsphilosophie, Heidelberg: C. F. Müller.

RAWLS, J. (2002), La justicia como equidad. U na reformulación, Barcelona: Paidós. 
Ritsert, J. (1997), Gerechtigkeit und Gleichheit, M ünster: Dampfboot. Schmitт, C. (1982), Teoría de la constitución, Madrid: Alianza.

Schum Peter, J. A. (1976), Capitalism, Socialism and D emocracy, Londres: Routledge.

Smith, A. (1993), An Inquiry into the Nature and Causes of the Wealth of Nations, Oxford: Oxford University Press.

Weber, M. (1991), Escritos políticos, Madrid: Alianza.

Fecha de recepción: 13 de julio de 2009 Fecha de aprobación: 2 de febrero de 2010 